\title{
Financial Constraints and Multilevel Perspective: The Case of the Italian Manufacturing Enterprises
}

\author{
Edgardo Sica \\ University of Foggia, Foggia, Italy
}

\begin{abstract}
Following a multi-level perspective (MLP), a sustainability transition is the consequence of destabilization pressures from the landscape level that are exerted towards the current unsustainable regime contributing thus to the emergence of niche-level eco-innovations (EI). However, the existence of financial barriers to eco-innovative companies may hinder the development and diffusion of EIs at regime level, jeopardising the creation of windows of opportunity that are necessary for niche-level innovations to succeed. In this framework, the present paper investigates to what extent financial constraints are hampering the eco-innovative investments at regime level, by employing an ad hoc designed survey addressed to a sample of Italian manufacturing enterprises. Results reveal the existence of significant financial barriers to eco-innovative companies which are hindering the development and adoption of incremental technological EIs and organizational EIs at regime level, delaying the transition towards a more sustainable regime. Moreover, findings suggest that environmental reputation of companies can positively contribute to reducing asymmetric information in eco-innovative investments, relieving thus the financial constraints faced by eco-innovative enterprises.
\end{abstract}

Keywords: sustainability, eco-innovations (EIs), socio-technical transitions, financial constraints

\section{Introduction}

In the last 50 years, the need to meet the increasing demand for energy, food, and water has produced a rapid and extensive alteration of ecosystems, soil degradation, loss of biodiversity, and deforestation. At the same time, the growing process of industrialisation across the world has contributed to rising greenhouse gas emissions, air and water pollution, expanding waste volumes, desertification, and chemical pollution. Given these premises, the key challenge for the next years seems to be reducing the environmental footprint of production and consumption patterns by promoting the transition towards a more resource efficient economy (LIFE, 2009).

To make this happen, a deep change in the way goods are produced and used is needed, along with a shift in the existing socio-technical structures. Although such a change is typically associated with higher economic costs, it hides a large economic potential along with numerous opportunities for companies to engage in innovations which contribute to the improvement of environmental quality. This kind of innovations, generally labelled as "eco-innovations" (or, alternatively, as “environmental-innovations”, "green-innovations”, or "sustainable-innovations"), plays a crucial role in the transition process towards a green economy, by contributing to managing successfully the environment.

Edgardo Sica, assistant professor of Economics, Department of Economics \& Star Energy Group, University of Foggia. Email: edgardo.sica@unifg.it. 
Eco-innovations (henceforth "EIs") include all types of innovations which avoid or reduce environmental damages, contributing thus to an improved quality of the environment (Huber, 2004; 2005). They are potentially developed in any economic sector and not exclusively in eco-industries which specifically produce goods and services to prevent or limit environmental burdens. EIs involve technological innovations (i.e., product and process innovations) as well as non-technological innovations (i.e., organizational changes in the management of firms, along with changes at social and political levels) (Kemp, Arundel, \& Smith, 2001). Moreover, according to the intensity of innovation, EIs can also be classified as "incremental" or "radical" (see Freeman, Clark, \& Soete, 1982). Incremental EIs take place more or less continuously in companies, although at a dissimilar rate in different industries and over time periods. By contrast, radical EIs are discontinuous events which are unevenly distributed over sectors and time and are the result of a deliberate research and development process in companies.

Following the multi-level perspective (MLP) approach initially introduced by Rip and Kemp (1998) and then refined by Geels (2002), a transition towards more sustainable regimes can occur only when radical technological EIs can enter the current (unsustainable) regime. However, since the existing systems are “locked in” on many dimensions (e.g., economic, social, cultural, infrastructural, regulatory, etc.) (Elzen, Geels, \& Green, 2004), the possibility for radical technological EIs to succeed depends upon the contribution of incremental technological EIs and organizational EIs in creating windows of opportunities at regime level for radical technological EIs to emerge. On this ground, the process of sustainability transition can be seriously hindered by the existence of companies' financial constraints which can hinder the development and the adoption of EIs, preventing thus the creation of favourable conditions at regime level for a systemic change to occur.

In this framework, the present study aims to increase knowledge about sustainability transitions by investigating the extent to which financial constraints hinder the eco-innovative decisions of regime-level companies. The paper is organised as follows. Section 2 illustrates the background model. Section 3 explains the role of financial constraints within the MLP approach. Section 4 describes the methodology adopted. Section 5 depicts the empirical results achieved. Finally, Section 6 ends with some concluding remarks.

\section{The Background Model}

In the frame of evolutionary theories of innovations, the MLP allows capturing the complexity of interlinked relationships as well as the underlying driving forces that can affect socio-technical transitions towards more sustainable regimes. The MLP describes socio-technical transitions in terms of three linked levels: landscape, regime, and niche.

The landscape (macro-level) is an external structure or context for interactions of actors where a number of different forces act, exerting pressure upon the regime and, eventually, on the niche through social, political, and economic channels (Geels, 2002).

The regime (meso-level) can be defined as a relatively stable configuration of institutions, techniques, and artefacts, as well as rules, practices, and networks that determine the "normal" development and use of technologies (Berkhout, Smith, \& Stirling, 2004; Rip \& Kemp, 1998).

Finally, the niche (micro-level) consists of protected spaces or "incubator rooms" where actors develop and test promising technologies that deviate from existing regimes. Niches aim at enhancing the further development and the rate of application of new technologies and learning about their desirability (Geels \& Schot, 2007; Kemp, Schot, \& Hoogma, 1998). 
A socio-technical transition is the consequence of the co-evolutionary dynamics of the three above-mentioned levels. In particular, it occurs when pressures from the landscape level couple with changes in the socio-technical regime and with sufficiently developed niche-innovations. Therefore, the ultimate success of a socio-technical transition crucially depends upon the following interactions:

(1) External-to-the-niche conditions that develop at landscape level and exert destabilization pressures on the regime and, eventually, on the niche;

(2) Changes in the socio-technical regime which create windows of opportunity for niche-innovations to emerge;

(3) Sufficiently developed niche-innovations that are ready to enter and replace the current regime.

It is worth noting that the above three conditions do not cause or drive unidirectionally the others but they link up with, and reinforce, one with each other following a process of "circular causality" (Geels, 2011).

Moving towards the specific case of sustainability transitions (i.e., socio-technical transitions towards more sustainable regimes), the eco-innovative behaviour of regime and niche-level companies plays therefore a central role in achieving sustainability, as reported in Figure 1.

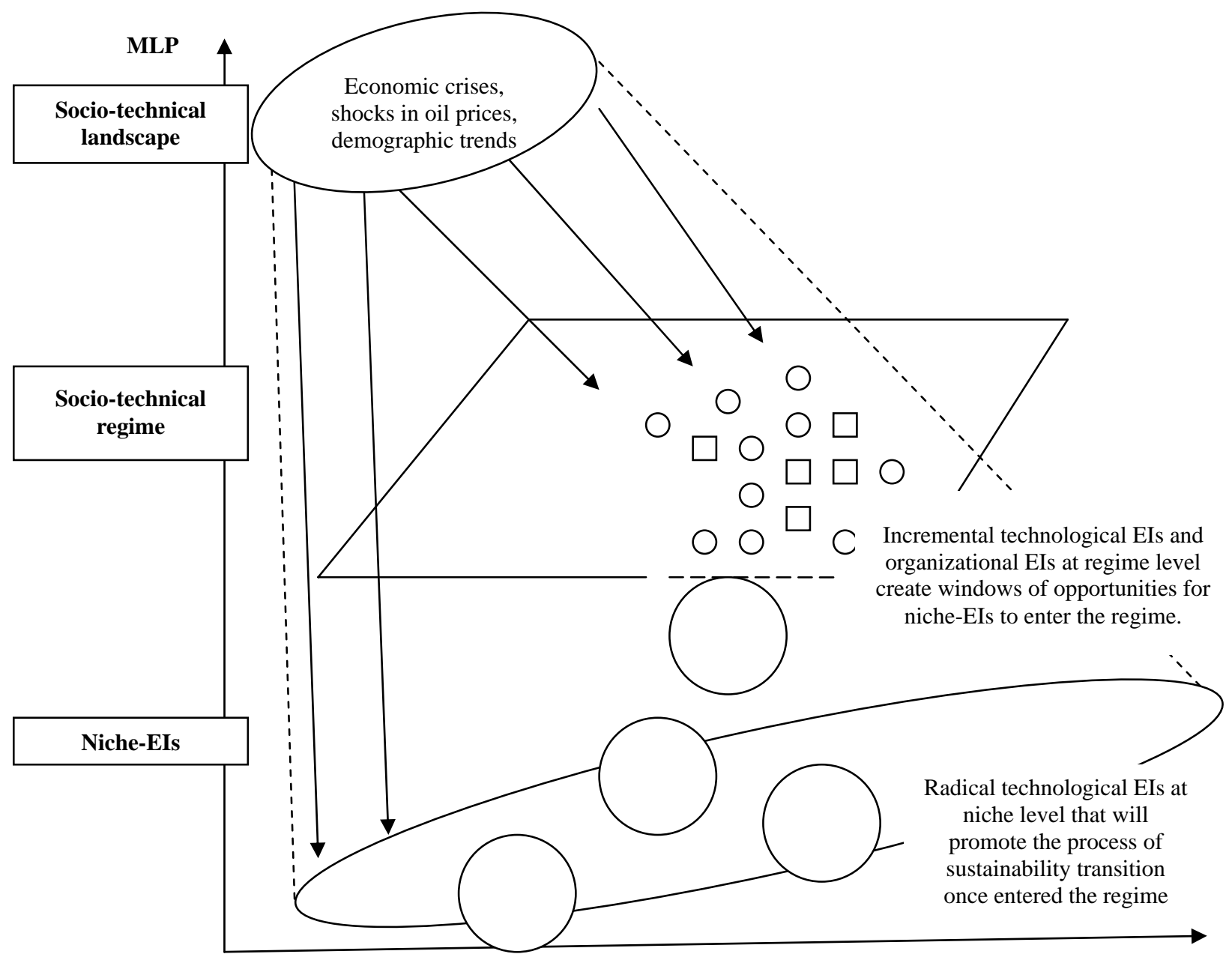

Figure 1. EIs and sustainability transitions. Source: own elaboration. 
At landscape level, a number of exogenous forces (e.g., economic crises, shocks in oil prices, demographic trends) can exert a destabilization pressure towards a sustainability transition, by driving the eco-innovative behaviour of companies at regime and niche levels. Such forces create favourable conditions for a paradigmatic shift towards new green patterns of consumption and production (Geels, 2013).

At regime level, incremental technological EIs and organizational EIs (respectively little circles and squares in Figure 1) create adjustments for the emergence of niche-EIs. Incremental technological EIs are mainly (although not exclusively) curative technologies which repair environmental damages after they have occurred and/or additive technologies which are employed to remove contaminants after they have produced but before they are disposed of. Organizational EIs are the incorporation of environmental perspectives and environmental-respectful awareness into companies' strategies and practices and are generally complementary to the adoption of technological EIs at company level.

At niche level, radical technological EIs (big circles in Figure 1) have the possibility of being experimented, providing thus the seeds for a systemic sustainable change to occur. However, the possibility for them to replace the current regime crucially depends upon the diffusion of incremental technological EIs and organizational EIs at regime level which create windows of opportunities (Geels, 2011; Schot \& Geels, 2008) to niche-EIs in order to enter the regime.

\section{MLP and Financial Constraints}

Companies may recur to internal and/or external funds to finance EIs. In general terms, the problem of how to finance an investment project (i.e., whether to recur to internal or external financing and, in the latter case, whether to recur to debts or equity) represents a crucial decision for companies (Santarelli, 1995). At regards, companies seem to exhibit a strict ordering or "hierarchy of finance" by using internal financing first, then debt, and only when such option is exhausted, turning to equity (Myers, 1984). The existence of asymmetric information between companies and perspective investors determines the imperfect substitutability between internal and external financing and the consequent risk for eco-innovating companies to be financially constrained in case of internal funds shortage (Marabel Romo, 2014; Canepa \& Stoneman, 2003; Hall, 2002).

From the MLP perspective, the existence of financial constraints can affect the possibility for sustainability transitions to occur by preventing niche-EIs to enter the current regime and succeed. This can happen by means of the joint action at two levels:

(1) At regime level, since financial constraints may hinder the eco-innovative behaviour of companies. By preventing the development and adoption of incremental technological EIs and organizational EIs, financial constraints hamper de facto the creation of favourable conditions (windows of opportunity) for niche-EIs to emerge;

(2) At niche-level, since financial constraints may hinder the development and diffusion of radical technological EIs which can promote the transition.

The inability of eco-innovating companies to fund their desired investment projects creates therefore a barrier to the alignment process between socio-technical regime and niche-EIs which is necessary for a sustainability transition to take place. In other words, when pressures at landscape level push enterprises to eco-innovate at regime and niche levels, the existence of financial constraints may limit the degree of companies' eco-innovativeness, delaying thus the possibility for a systemic change to occur. Indeed, many incremental technological EIs and organizational EIs at regime level are not developed or adopted and the same applies to many promising radical EIs at niche level. 
In this framework, a possible way to reduce the problem of financial constraints by lightening information asymmetries towards perspective investors stems from the environmental reputation of eco-innovating companies. Environmental reputation can be considered as a signal sent from companies to lenders to indicate their lower perceived compliance costs and liabilities (Lee \& Hutchison, 2005). Within the above model, environmental reputation can contribute to creating the favourable conditions at regime level for fostering the sustainability transition allowing niche-level EIs to enter the current regime.

\section{Methodology}

The present study focuses upon the socio-technical regime, by investigating the impact that financial constraints can exert upon the eco-innovative behaviour of regime-level companies. In other words, it investigates to what extent financial constraints may jeopardise the possibility for sustainability transitions to occur by hampering the development and adoption of incremental technological EIs and organizational EIs. The study employs a novel approach for recognising eco-innovative enterprises at regime level, by using an ad hoc designed questionnaire where companies surveyed are not pre-supplied with a definition of EI, but, instead are asked to offer their own definition of what an EI is. Allowing respondents to provide their own opinion on what EIs are helps to understand their viewpoint on the "who" eco-innovates (Arundel, Smith, Patel, \& Sirilli, 1998) and avoids forcing them to adopt a definition which they may not understand or agree with, creating thus a sense of coercion that might alienate them. Since EIs can be potentially developed in any productive sector, this approach allows identifying eco-innovating companies that operate in any productive sector and not only in the greentech industry.

The questionnaire was administrated to a sample of 384 Italian manufacturing companies, drawn from the AIDA (Analisi Informatizzata Delle Aziende) database provided by the Bureau Van Dijk. The sample was selected by using a stratified random sampling strategy to avoid that some companies of the population were less likely to be included in the sample than others. After grouping companies into distinct, independent (not overlapping) strata, a random sample from any stratum was chosen in proportion to each stratum size (Oslo Manual, 2005, pp. 117-134). More specifically, strata taken into account were:

(1) Sectors, by considering all manufacturing industries according to the NACE Rev.2 codes classification (from 10 to 33);

(2) Company size, by taking into account large and small- and medium-sized enterprises (SMEs) according to the European Commission Recommendation 2003/361/EC (i.e., SMEs are companies which employ fewer than 250 workers);

(3) Geographical area, by dividing Italy into three macro-regions according to their level of per capita GDP (North, Centre, and South).

Questionnaires were administrated by means of the CAWI (Computer-Assisted Web Interviewing) technique. Companies were firstly contacted via telephone with the aim to inform them about the research purposes and to identify the most suitable person in charge of the enterprise to answer the questionnaire (e.g., director, strategic planning manager, etc.). A web link to the questionnaire was then sent to the respondent's email address. The targeted number of 384 valid questionnaires was reached after contacting 2,454 Italian companies via telephone between May 2012 and February 2013, with a response rate of $15.7 \%$. 


\section{Results}

The percentage of companies surveyed that declared to be eco-innovative was $59.4 \%$ of total (absolute percentage) and $72.6 \%$ of the innovative firms (relative percentage). Figure 2 reports the sources of finance for the Italian eco-innovative firms surveyed.

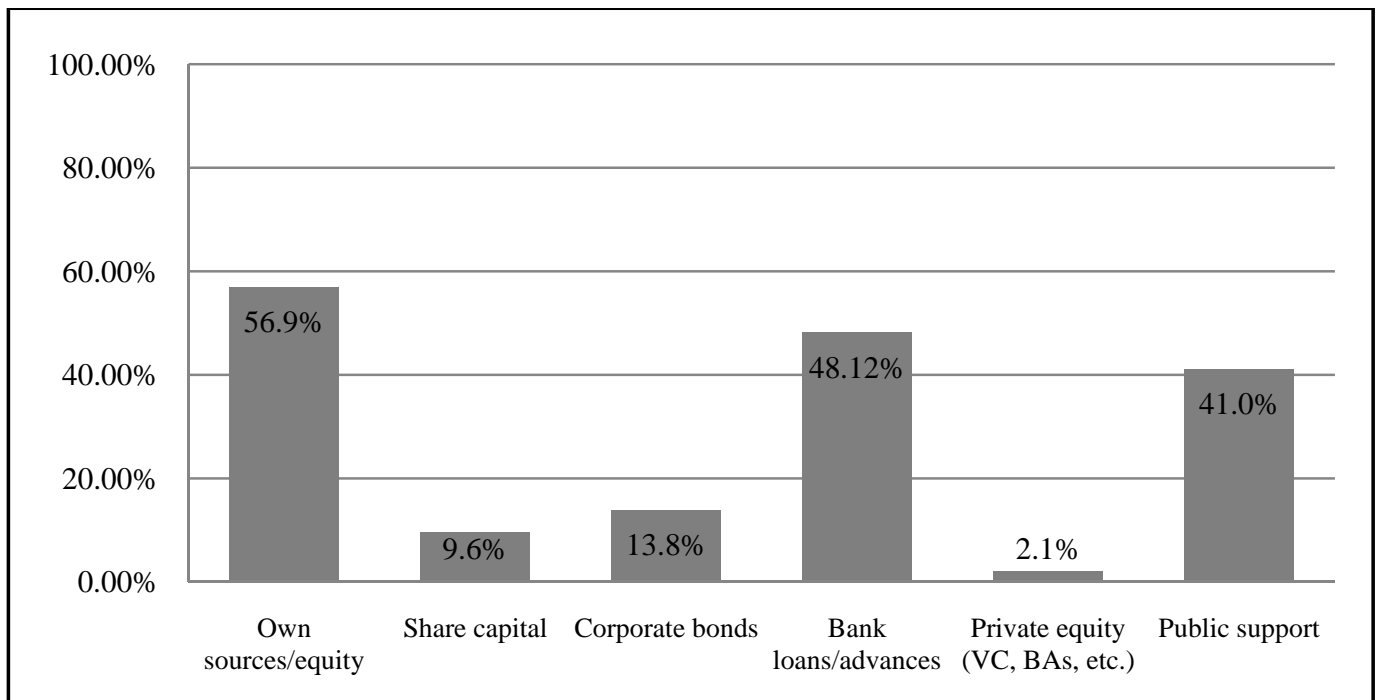

Figure 2. Sources of finance for the Italian eco-innovative firms surveyed (percentage values). Source: own elaboration.

EIs were financed mainly by own sources (56.9\% of companies), followed by bank loans/advances (48.12\%) and public support (41.0\%). It is worth noting the low recourse of companies surveyed to corporate bonds (13.8\%), share capital/equities (9.6\%), and private equity (2.1\%). This result can be explained in the light of the specific aspects of the Italian productive system which is typically characterised by the huge presence of SMEs and micro firms that employ large amounts of internal sources and bank loans to finance their innovative projects.

Figure 3 reports the main barriers faced by regime-level companies when seeking to finance their eco-innovative projects. More specifically, the figure reports, for any option provided, the percentage of eco-innovative companies that rated that option as "very" or "quite" important. Data are organised by company size and age since both of them can affect the extent to which companies are financially constrained (see Carreira \& Silva, 2010; Canepa \& Stoneman, 2008; Hyytinen \& Pajarinen, 2008).

Looking at Figures 3 and 4, results seem to suggest a large impact of financial barriers on the eco-innovative behaviour of firms, above all in case of SMEs and very young enterprises. The most relevant financial barrier faced by companies surveyed when seeking to finance their eco-innovative projects was represented by the different expected returns of financial suppliers compared to companies' business goals, which were rated as "very" or "quite" important barriers by $84.94 \%$ of companies. However, other options provided were rated as "very" or "quite" important financial barriers by the highest percentages of Italian companies (mainly SMEs), as in the case of "insufficient amount of collateral" (83.26\%). This result should be analysed in the light of the characteristics of the Italian financial system where the pattern of industrial finance is mainly bank-centred and consequently the existence of collateral is a crucial element for firms to get financed. Other very significant financial barriers are represented by "finance not tailored to small-scale investment needs" (73.22\%), and "limited resources dedicated to seeking or securing finance” (71.13\%). 


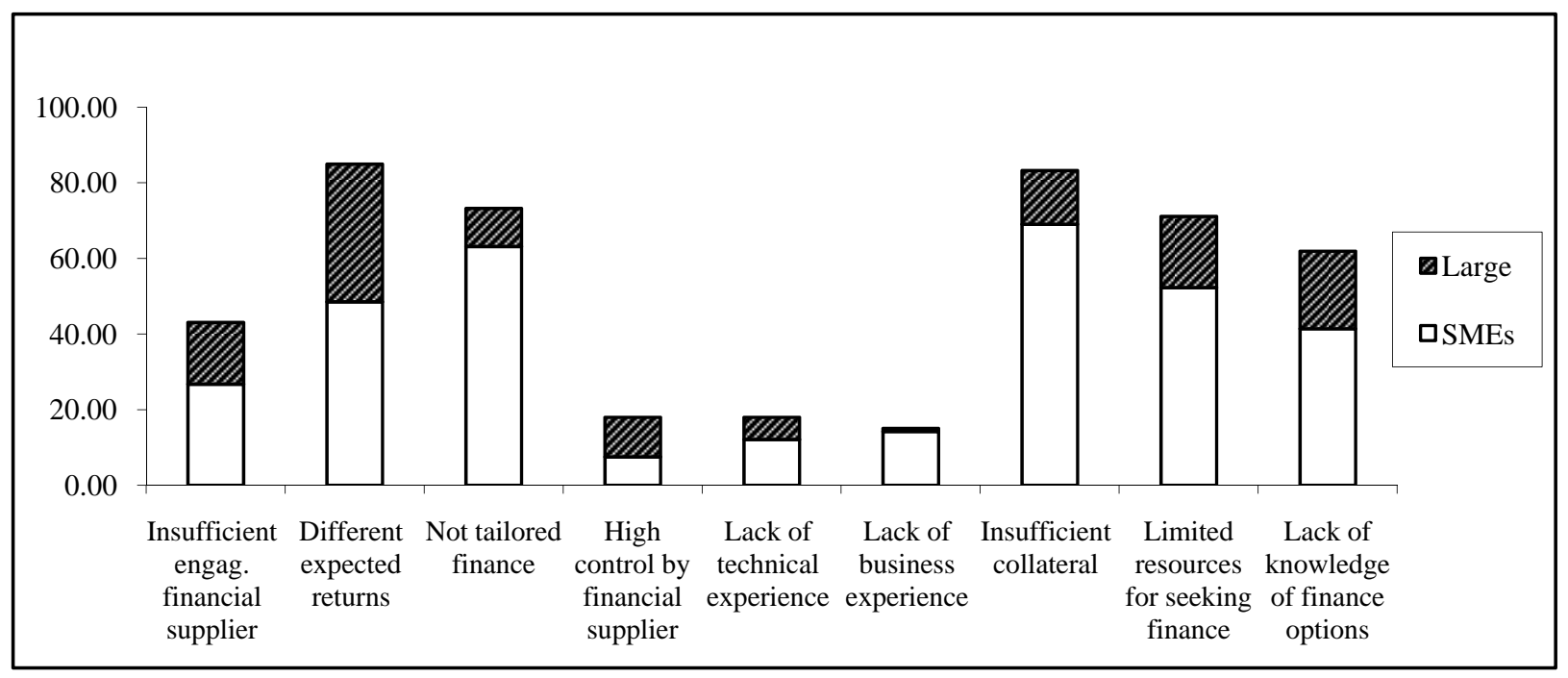

Figure 3. Financial barriers faced by eco-innovative companies at regime level by size (percentage values). Source: own elaboration.

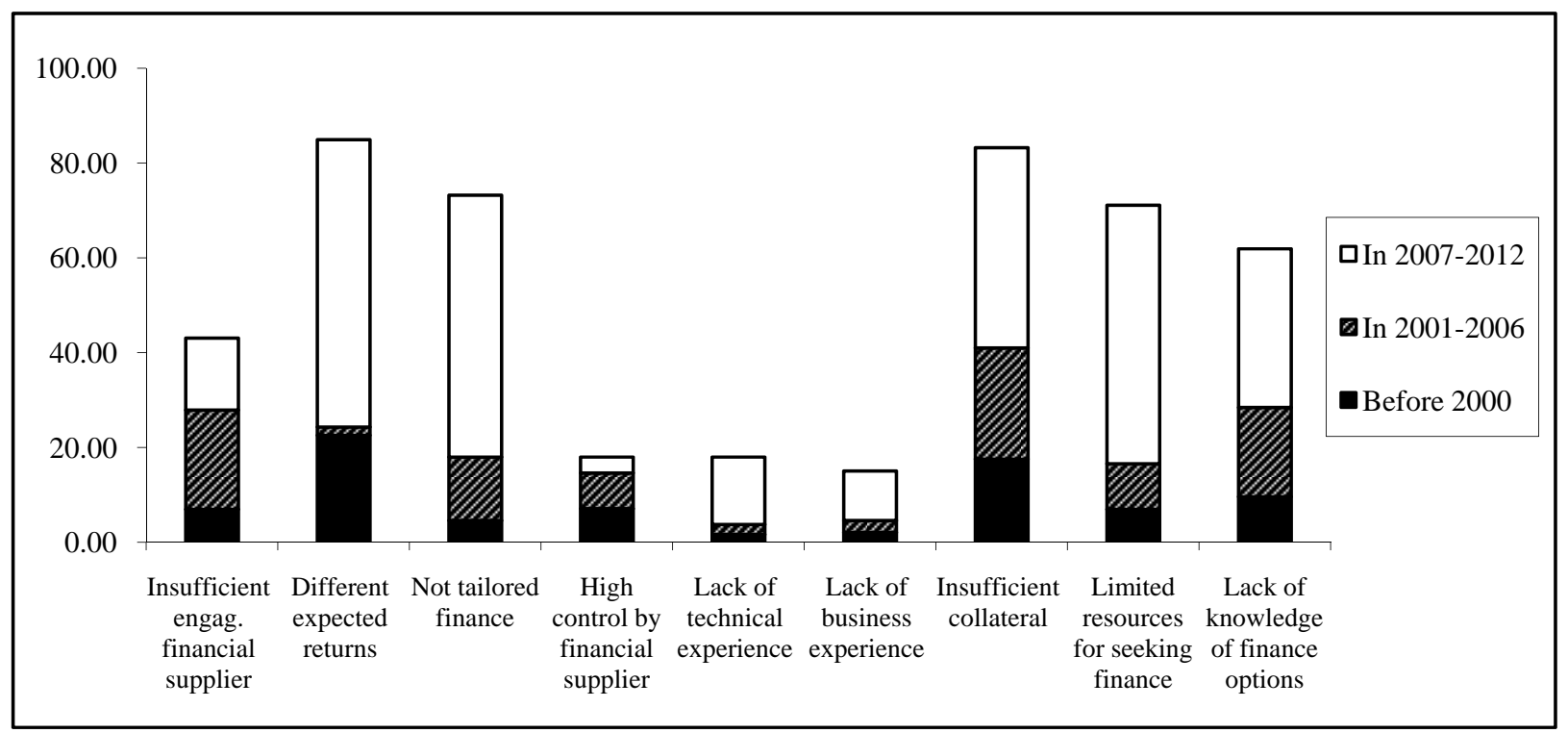

Figure 4. Financial barriers faced by eco-innovative companies at regime level by age (percentage values). Source: own elaboration.

Finally, Figure 5 provides companies' viewpoint about the role of environmental reputation in seeking to finance their eco-innovative projects.

Data reveal that $60.7 \%$ of eco-innovative companies surveyed believe that the environmental reputation of enterprises can influence the possibility to gain finance. Moreover, $69.5 \%$ of enterprises have declared that funding eco-innovative projects is easier than other types of investments, although this seems not to prevent companies from facing financial barriers and even to be financially constrained. On one hand, such findings could support the possibility that a good environmental reputation reduces the asymmetric information of companies towards their prospective investors and the consequent problems of financial constraints. On the other hand, this result can be due to the increasing attention of financial markets and intermediaries towards green investments that provide new financial solutions tailored to eco-innovating enterprises. 


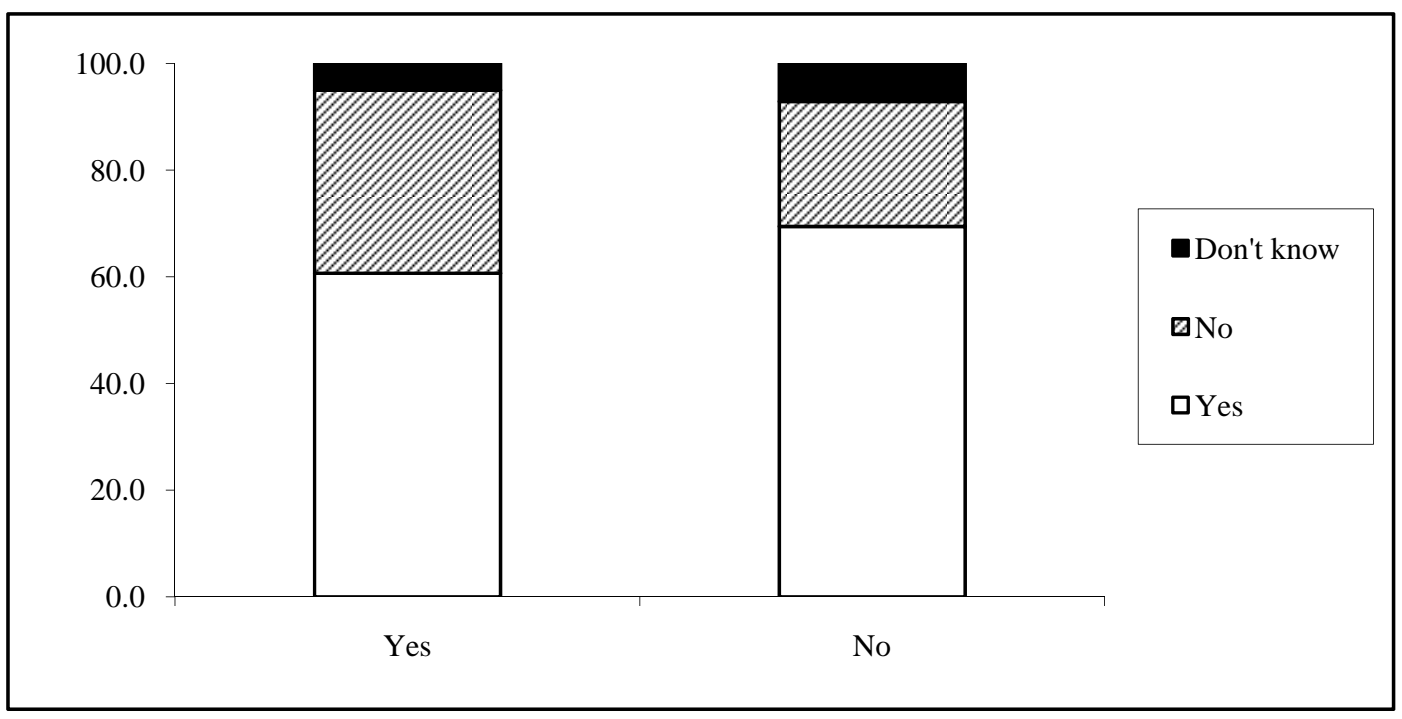

Figure 5. Role of environmental reputation for eco-innovative companies at regime level.

\section{Conclusions}

The present study has analysed the impact that financial constraints can exert upon the possibility for a sustainability transition to occur by investigating the case of eco-innovative enterprises at regime level. Results reveal that a large percentage of Italian manufacturing companies surveyed have faced "very important" financial barriers when seeking for external funds, above all in terms of different expected returns of financial suppliers compared to companies' business goals, insufficient amount of collateral, finance not tailored to small-scale investment needs, and limited resources dedicated to seeking or securing finance. On one hand, the existence of significant financial barriers to eco-innovative companies is hindering the development and adoption of incremental technological EIs and organizational EIs at regime level, delaying the alignment process among landscape, regime, and niche that is necessary for a transition towards more sustainable regimes to occur. On the other hand, it seems that environmental reputation of companies can positively contribute to reducing asymmetric information in eco-innovative investments, relieving the financial constraints faced by eco-innovative enterprises.

\section{References}

Arundel, A., Smith, K., Patel, P., \& Sirilli, G. (1998). The future of innovation measurement in Europe - Concepts, problems and practical directions. IDEA Paper Series No. 3.

Berkhout, F., Smith, A., \& Stirling, A. (2004). Socio-technological regimes and transition contexts. In B. Elzen, F. W. Geels, \& K. Green (Eds.), System innovation and the transition to sustainability: Theory, evidence and policy. Cheltenham, UK: Edward Elgar.

Canepa, A., \& Stoneman, P. (2003). Do financial factors constrain innovation? A European cross country study. In M. Waterson, (Ed.), Competition, monopoly and corporate governance: Essays in honour of Keith Cowling. London: Edward Elgar.

Canepa, A., \& Stoneman, P. (2008). Financial constraints to innovation in the UK: Evidence from CIS2 and CIS3. Oxford Economic Papers, 60(4), 711-730.

Carreira, C., \& Silva, F. (2010). No deep pockets: Some stylized empirical results on firms' financial constraints. Journal of Economic Surveys, 24(4), 731-753.

Elzen, B., Geels, F. W., \& Green, K. (2004). System innovation and the transition to sustainability: Theory, evidence and policy. Cheltenham, UK: Edward Elgar. 
Freeman, C., Clark, J., \& Soete, L. (1982). Unemployment and technical innovation: A study of long waves and economic development. London: Frances Printer.

Geels, F. W. (2002). Technological transitions as evolutionary reconfiguration processes: A multi-level perspective and a case-study. Research Policy, 31(8-9), 1257-1274.

Geels, F. W. (2011). The multi-level perspective on sustainability transitions: Responses to seven criticisms. Environmental Innovation and Societal Transitions, 1(1), 24-40.

Geels, F. W. (2013). The impact of the financial-economic crisis on sustainability transitions: Investment, governance and public discourse. Environmental Innovation and Societal Transitions, 6, 67-95.

Geels, F. W., \& Schot, J. (2007). Typology of sociotechnical transition pathways. Research Policy, 36(3), 399-417.

Hall, B. H. (2002). The financing of research and development. Oxford Review of Economic Policy, 18(1), 35-51.

Huber, J. (2004). New technologies and environmental innovations. Cheltenham: Edward Elgar.

Huber, J. (2005). Key environmental innovations. FEEM Working Paper 33, Fondazione ENI Enrico Mattei, Milan.

Hyytinen, A., \& Pajarinen, M. (2008). Opacity of young businesses: Evidence from rating disagreements. Journal of Banking \& Finance, 32(7), 1234-1241.

Kemp, R., Arundel, A., \& Smith, K. (2001). Survey indicators for environmental innovation. Paper presented at Conference “Towards Environmental Innovation Systems”, Garmisch-Partenkirchen.

Kemp, R., Schot, J., \& Hoogma, R. (1998). Regime shifts to sustainability through processes of niche formation: The approach of strategic niche management. Technology Analysis and Strategic Management, 10(2), 175-198.

Lee, T. M., \& Hutchison, P. D. (2005). The decision to disclose environmental information: A research review and agenda. Advances in Accounting, 21, 83-111.

LIFE. (2009). Getting more from less: LIFE and sustainable production in the EU. European Commission.

Marabel Romo, J. (2014). Investment decisions with financial constraints. Evidence from Spanish firms. Quantitative Finance, 14(6), 1079-1095. doi: 10.1080/14697688.2013.785635

Myers, S. C. (1984). The capital structure puzzle. Journal of Finance, 39(3), 574-592.

Oslo Manual. (2005). Guidelines for collecting and interpreting innovation data. OECD.

Rip, A., \& Kemp, R. (1998). Technological change. In S. Rayner, \& L. Malone (Eds.), Human choice and climate change (Vol. 2: Resources and technology; pp. 327-399). Washington, DC: Batelle Press.

Santarelli, E. (1995). Finance and technological change: Theory and evidence. New York, NY: St. Martin’s Press, Inc..

Schot, J., \& Geels, F. W. (2008). Strategic niche management and sustainable innovation journeys: Theory, findings, research agenda, and policy. Technology Analysis and Strategic Management, 20(5), 537-554. 